\title{
PREDIKSI KINERJA SIMPANG TAK BERSINYAL PADA JL. BOULEVARD - JL. ADHYAKSA BARU
}

\author{
St. Maryam $\mathrm{H}^{1}$, Lambang Basri Said ${ }^{2}$, Muhammad Syaifullah ${ }^{3}$
}

\author{
${ }^{1}$ Dosen Magister Teknik Sipil PPS-UMI Makassar. \\ Jl. Urip Sumoharjo No.225 Makassar, Telp.454534,Email : maryammaladia@gmail.com \\ 2 Dosen Magister Teknik Sipil PPS-UMI Makassar. \\ Jl.Urip Sumoharjo No.225 Makassar,Telp.454534,Email : elbasriumi@yahoo.com \\ ${ }^{3}$ Karyawan PT. Aphasko Utamajaya. \\ Jl.Andi Djemma No.15Makassar.Email : ipulcool@gmail.com
}

\begin{abstract}
Abstrak
Kondisi simpang tak bersinyal jalan Boulevard - jalan Adhyaksa Baru mengalami kemacetan hampir setiap harinya terutama pada jam-jam puncak yaitu antara pukul 16.00 wita sampai dengan pukul 18.00 wita. Hal ini disebabkan adanya pergerakan kendaraan dari arah timur jalan A. P. Pettarani menuju jalan Boulevard, pada lokasi ini terdapat salah satu pusat perbelanjaan tersibuk di Kota Makassar. Survey ini dilakukan pada pukul 06.00 - 20.00 pada hari Jumat, Sabtu, Minggu, dan Senin selama 3 bulan.Simpang tak bersinyal jalan Boulevard - jalan Adhyaksa baru Menggunakan peralatan alat hitung manual counter, dengan memiliki kapasitas $33.397 \mathrm{smp} / \mathrm{jam}$ sedangkan pada simpang jalan Boulebard - jalan Bougenville memiliki kapasitas $4277 \mathrm{smp} / \mathrm{jam}$. Pada kondisi eksisting arus lalu lintas pada simpang tak bersinyal pertama (Q) sebesar 21.949 smp/jam dengan derajat kejenuhan (DS) $0,657<0,85$, sedangkan pada tahun 2023 dengan kapasitas simpang yang sama, arus lalu lintas pada simpang tak bersinyal diprediksi sebesar 33.398 smp/jam dengan derajat kejenuhan $0,88>0,85$.
\end{abstract}

Kata Kunci : Simpang tak bersinyal. Kapasitas simpang, Derajat kejenuhan.

\section{PENDAHULUAN}

\subsection{Latar Belakang Masalah}

Kondisi simpang tak bersinyal jalan Boulevard - jalan Adhyaksa Baru mengalami kemacetan hampir setiap harinya. Hal ini disebabkan adanya pergerakan kendaraan dari arah timur jalan A. P. Pettarani menuju jalan Boulevard, pada jalan Boulevard ini terdapat salah satu pusat perbelanjaan tersibuk di Kota Makassar yaitu Mall Panakukkang. Meskipun terdapat beberapa simpang yang diharapkan dapat membantu untuk mengurai kemacetan, namun sampai saat ini pola pergerakan yang terjadi belum dapat terlihat secara jelas sehingga terjadi pencampuran moda pergerakan yang melintas di jalan Boulevard tersebut. Apalagi untuk menuju jalan adhyaksa baru dari arah boulevard terdapat beberapa titik persimpangan tak bersinyal.

Kemacetan yang terjadi pada ruas jalan ini, terjadi hampir setiap harinya pada jam puncak yaitu antara pukul 16.00 wita sampai dengan pukul 18.00 wita. Gangguan lalulintas ini terjadi karena adanya penurunan kinerja jalan, dimana terdapat penambahan volume lalu lintas jalan yang mengakibatkan kemacetan lalu lintas pada ruas jalan sekitar jalan tersebut.

\subsection{Rumusan Masalah}

1. Bagaimana kinerja simpang tak bersinyal pada ruas jalan boulevard - adhyaksa baru.

2. Bagaimana kinerja simpang tak bersinyal pada tahun 2023 .

\subsection{Tujuan Penelitian}


1. Menganalisis kinerja simpang tak bersinyal pada pada ruas jalan boulevard - adhyaksa baru.

2. Menganalisis kinerja simpang tak bersinyal pada tahun 2023.

\section{METODE PENELITIAN}

\subsection{Metode Analisis Data}

Penelitian ini bertujuan untuk menganalisis kinerja simpang tak bersinyal pada pada ruas jalan boulevard - adhyaksa baru pada kondisi eksisting dan pada tahun 2023 ..

Menganalisis kinerja simpang tak bersinyal pada tahun 2023 Untuk mencapai tujuan dan sasaran dari studi ini, maka digunakan pendekatan analisis deskriptif eksploratif. Dimana penelitiannya berbentuk studi kasus dengan menggunakan metode survei dan pengamatan langsung dilapangan terhadap kondisi ruas jalan dan volume kendaraan agar dapat diketahui bagaimana kinerja lalu lintas.

\subsection{Pelaksanaan Penelitian}

Penelitian ini dilakukan selama 3 bulan, mulai dari Februari 2018 sampai dengan April 2018. Dimana setiap minggu nya traffic counting dilakukan selama 4 hari yaitu senin, jumat, sabtu, dan minggu. Volume lalulinas dicatat per 15 menit agar mendapatkan data yang lebih akurat yang kemudian diolah untuk menjadi volume lalulintas tiap jam. Untuk menentukan jam puncak yaitu dengan memilih volume lalulintas tiap jam yang terbesar. Setelah didapatkan data volume lalu lintas tiap jam (smp/jam) dan periode pengamatan jam puncak (pagi, siang, sore dan malam). Pengambilan waktu dilaksanakan mulai jam 06:00 pagi sampai jam 20:00 malam pada masingmasing simpang.

\section{HASIL DAN PEMBAHASAN}

\subsection{Kondisi Lapangan}

Tabel 1. Data Kondisi Lapangan

\begin{tabular}{|c|c|c|c|c|c|c|c|c|c|c|c|}
\hline \multirow[t]{4}{*}{ Pilihan } & \multirow{3}{*}{$\begin{array}{c}\text { Jumlah lengan } \\
\text { simpang }\end{array}$} & \multicolumn{7}{|c|}{ Lebar pendekat $(\mathrm{m})$} & \multirow{2}{*}{\multicolumn{2}{|c|}{$\begin{array}{l}\text { Jumlah lajur } \\
\text { Gambar B-1:2 }\end{array}$}} & \multirow{3}{*}{$\begin{array}{c}\text { Tipe } \\
\text { simpang } \\
\text { Tbl B-1:1 }\end{array}$} \\
\hline & & \multicolumn{3}{|c|}{ Jalan minor } & \multicolumn{3}{|c|}{ Jalan utama } & \multirow{3}{*}{$\begin{array}{c}\text { Lebar } \\
\text { pendekat } \\
\text { rata-rata } W_{1} \\
8\end{array}$} & & & \\
\hline & & $\mathrm{W}_{\mathrm{A}}$ & $\mathrm{W}_{\mathrm{c}}$ & $W_{A C}$ & $W_{B}$ & $W_{D}$ & $\mathrm{~W}_{\mathrm{BD}}$ & & $\begin{array}{l}\text { Jalan } \\
\text { minor }\end{array}$ & $\begin{array}{l}\text { Jalan } \\
\text { utama }\end{array}$ & \\
\hline & 1 & 2 & 3 & 4 & 5 & 6 & 7 & & 9 & 10 & 11 \\
\hline 1 & 4 & 2.750 & 2.750 & 2.750 & 9.000 & 18.000 & 13.500 & 8.125 & 2.000 & 2.000 & 422 \\
\hline & & & & & & & & & & & \\
\hline & & & & & & & & & & & \\
\hline & & & & & & & & & & & \\
\hline
\end{tabular}

(sumber: hasil Pengukuran Lapangan,2018)

Data volume lalulintas yang digunakan yaitu data pada hari Jumat 16 Februari 2018, arus puncak dari arah Utara terjadi pada pukul 08.45 - 09.45, pada arah Selatan terjadi jam puncak pada pukul 16.00 - 16.15, pada arah Timur jam puncak terjadi pukul 16.15 - 17.15, pada arah Barat, data ini dianggap mewakili data-data lainnya karena mempunyai volume arus lalulintas tertinggi (jam puncak tinggi).

\subsection{Kinerja Simpang Tak Bersinyal Jl. Boulevard - Jl. Adhyaksa Baru Eksisting}

1) Perhitungan Kapasitas

Perhitungan kapasitas bertujuan untuk mengetahui seberapa besar kapasitas di persimpangan Jl. Boulevard -Jl. Adhyaksa Baru pada kondisi eksisting.

Tabel 2. Perhitungan Kapasitas 


\begin{tabular}{|c|c|c|c|c|c|c|c|c|}
\hline \multirow{3}{*}{$\begin{array}{c}\text { Kapsitas } \\
\text { Dasar } \\
\begin{array}{c}\text { Co } \\
\text { smp/jam }\end{array}\end{array}$} & $\begin{array}{c}\text { Lebar } \\
\text { pendekat } \\
\text { rata-rata } \\
\text { FW }\end{array}$ & $\begin{array}{c}\text { Median } \\
\text { jalan } \\
\text { utama } \\
\text { FM }\end{array}$ & $\begin{array}{c}\text { Ukuran } \\
\text { Kota } \\
\text { Fcs }\end{array}$ & $\begin{array}{c}\text { Fambatan } \\
\text { Samping } \\
\text { FRSU }\end{array}$ & $\begin{array}{c}\text { Belo } \\
\text { k kiri } \\
\text { FLT }\end{array}$ & $\begin{array}{c}\text { Belok } \\
\text { kanan } \\
\text { FRT }\end{array}$ & $\begin{array}{c}\text { Rasio } \\
\text { Minor } \\
\text { Total } \\
\text { FMI }\end{array}$ & $\begin{array}{c}\text { Kapasita } \\
\text { s (C) } \\
\text { smp/jam }\end{array}$ \\
\hline 2900 & 7,736 & 1,05 & 1,00 & 0,95 & 1,636 & 1,00 & 0,912 & 333997 \\
\hline
\end{tabular}

(sumber: hasil perhitungan,2018)

2) Perilaku Lalu Lintas

Setelah diketahui besarnya kapasitas simpang, selanjutnya kita ingin mengetahui seberapa besar kinerja simpang tak bersinyal dengan membandingkan kapasitas simpang dengan arus lalu lintas yang melewatinya. Kinerja simpang pun dapat diketahui dengan melihat nilai derajat kejenuhan, tundaan dan peluang antrian yang terjadi di persimpangan $\mathrm{Jl}$. Boulevard -Jl. Adhyaksa Baru.

\begin{tabular}{|c|c|c|c|c|c|}
\hline $\begin{array}{c}\text { Kapasitas } \\
\text { Dasar } \\
\text { (Co) } \\
\text { Smp/jam }\end{array}$ & $\begin{array}{l}\text { Kapasitas } \\
\text { (C) } \\
\text { Smp/jam }\end{array}$ & $\begin{array}{c}\text { Arus } \\
\text { Lalulintas } \\
\text { (Q) } \\
\text { Smp/jam }\end{array}$ & $\begin{array}{l}\text { Derajat } \\
\text { Kejenuhan } \\
\text { (DS) }\end{array}$ & $\begin{array}{l}\text { Tundaan } \\
\text { (D) } \\
\text { Det/smp }\end{array}$ & $\begin{array}{c}\text { Peluang Antrian } \\
\text { (QP) } \\
\%\end{array}$ \\
\hline 2900 & 33397 & 21949 & 0,657 & 11,121 & $36,726-17,829$ \\
\hline
\end{tabular}

(sumber: hasil perhitungan,2018)

\subsection{Peramalan Volume Lalu Lintas pada Tahun 2023}

Peramalan volume lalu lintas kendaraan 2018 dilakukan dengan metode regresi linier pada PDRB kota Makassar untuk memperoleh data PDRB sampai dengan tahun 2023, kemudian dicari rata-rata i pertumbuhannya untuk digunakan dalam meramalkan volume kendaraan dengan menggunakan rumus $\mathrm{F}=\mathrm{P} \times(1+\mathrm{i})^{\mathrm{n}}$.

Regresi linier PDRB ditunjukkan oleh tabel 6 berikut ini. Proses regresi linier dihitung dengan menggunakan bantuan program Microsoft excel

Tabel 4 Hasil regresi linier PDRB

\begin{tabular}{|l|r|}
\hline $\begin{array}{l}\text { SUMMARY } \\
\text { OUTPUT }\end{array}$ \\
\hline \multicolumn{2}{|c|}{} \\
\hline \multicolumn{2}{|c|}{ Regression Statistics } \\
\hline Multiple R & 0.999177327 \\
\hline R Square & 0.998355332 \\
\hline Adjusted R Square & 0.997807109 \\
\hline Standard Error & 458065.2627 \\
\hline Observations & 5 \\
\hline
\end{tabular}

R square yang mendekati 1 menunjukkan bahwa data layak digunakan

\begin{tabular}{|l|c|c|c|c|}
\hline & \multicolumn{1}{|c|}{ Coefficients } & $\begin{array}{c}\text { Standard } \\
\text { Error }\end{array}$ & \multicolumn{1}{c|}{$t$ Stat } & $P$-value \\
\hline Intercept & -12366482236 & 291733922.7 & -42.38959296 & $2.88951 \mathrm{E}-05$ \\
\hline $\mathrm{X}$ Variable 1 & 6181464.706 & 144852.9547 & 42.67406708 & $2.83218 \mathrm{E}-05$ \\
\hline
\end{tabular}

(sumber: hasil perhitungan,2018) 
Perhitungan regresi linier tersebut menghasilkan persamaan 1 dengan variable bebas "tahun"

$\mathrm{Y}=\mathrm{A}+\mathrm{BX}$

$\mathrm{Y} \quad=12366482236+6181464,706 \mathrm{X}$

Keterangan :

$\mathrm{Y}=\mathrm{PDRB}$

$\mathrm{X} \quad=$ tahun

Persamaan 1. digunakan untuk menghitung PDRB pada tahun yang akan datang, hasil perhitungan ditunjukkan pada tabel 7. dibawah ini. Hasil perhitungan PDRB tersebut kemudian dicari rata-rata pertumbuhannya. Angka pertumbuhan didapatkan melalui persamaan 2

$i=\frac{(\operatorname{angka} P D R B \operatorname{tahun} n-\operatorname{angka} P D R B \operatorname{tahun} n-1)}{\operatorname{angka} P D R B \operatorname{tahun} n}$

Tabel 7. hasil perhitungan

\begin{tabular}{|c|c|l|l|}
\hline Tahun & \multicolumn{1}{|c|}{ PDRB } & i & i (\%) \\
\hline 2012 & $70,851,035.02$ & & \\
\hline 2013 & $76,907,410.80$ & 0.08 & 7.87 \\
\hline 2014 & $82,592,818.43$ & 0.07 & 6.88 \\
\hline 2015 & $88,750,158.38$ & 0.07 & 6.94 \\
\hline 2016 & $95,836,984.76$ & 0.07 & 7.39 \\
\hline 2017 & $101,532,075.60$ & 0.06 & 5.61 \\
\hline 2018 & $107,713,540.30$ & 0.06 & 5.74 \\
\hline 2019 & $113,895,005.01$ & 0.05 & 5.43 \\
\hline 2020 & $120,076,469.71$ & 0.05 & 5.15 \\
\hline 2021 & $126,257,934.42$ & 0.05 & 4.90 \\
\hline 2022 & $132,439,399.13$ & 0.05 & 4.67 \\
\hline 2023 & $138,620,863.83$ & 0.04 & 4.46 \\
\hline & Rata-rata & 0.06 & 5.91 \\
\hline
\end{tabular}

(sumber: hasil perhitungan,2018)

Nilai rata-rata $i=0,06$ digunakan dalam persamaan 3 . untuk meramalkan volume kendaraan pada tahun 2023

$\mathrm{F} \quad=\mathrm{P} \times(1+\mathrm{i})^{\mathrm{n}}$

Keterangan :

$\mathrm{F} \quad=$ volume kendaraan tahun rencana

P $\quad=$ data volume kendaraan pada tahun 2018

$\mathrm{n} \quad=$ jumlah tahun rencana

contoh perhitungan pada simpang 1 
Volume Kendaraan pada tahun 2023 utk LV (j1. Minor A)

$\mathrm{F} \quad=1776 \times(1+0,06)^{5}$

$=2377 \mathrm{kend} / \mathrm{jam}$

\subsection{Kinerja Simpang Tak Bersinyal Jl. Boulevard - Jl. Adhyaksa Baru Tahun 2023}

1) Perhitungan Kapasitas

Perhitungan kapasitas bertujuan untuk mengetahui seberapa besar kapasitas di persimpangan Jl. Boulevard -Jl. Adhyaksa Baru pada tahun 2023.

Tabel 8. Perhitungan Kapasitas

\begin{tabular}{|c|c|c|c|c|c|c|c|c|}
\hline \multirow{3}{*}{$\begin{array}{c}\text { Kapsitas } \\
\text { Dasar } \\
\text { Co } \\
\text { smp/jam }\end{array}$} & $\begin{array}{c}\text { Lebar } \\
\text { pendekat } \\
\text { rata-rata } \\
\text { FW }\end{array}$ & $\begin{array}{c}\text { Median } \\
\text { jalan } \\
\text { utama } \\
\text { FM }\end{array}$ & $\begin{array}{c}\text { Ukuran } \\
\text { Kota } \\
\text { Fcs }\end{array}$ & $\begin{array}{c}\text { Hambatan } \\
\text { Samping } \\
\text { FRSU }\end{array}$ & $\begin{array}{c}\text { Belo } \\
\text { k kiri } \\
\text { FLT }\end{array}$ & $\begin{array}{c}\text { Belok } \\
\text { kanan } \\
\text { FRT }\end{array}$ & $\begin{array}{c}\text { Rasio } \\
\text { Minor } \\
\text { Total } \\
\text { FMI }\end{array}$ & $\begin{array}{c}\text { Kapasit } \\
\text { as (C) } \\
\text { smp/ja } \\
\text { m }\end{array}$ \\
\hline 2900 & 7,736 & 1,05 & 1,00 & 0,95 & 1,636 & 1,00 & 0,912 & 33398 \\
\hline
\end{tabular}

(sumber: hasil perhitungan,2018)

2) Perilaku Lalu Lintas

Setelah diketahui besarnya kapasitas simpang, selanjutnya kita ingin mengetahui seberapa besar kinerja simpang tak bersinyal dengan membandingkan kapasitas simpang dengan arus lalu lintas yang melewatinya. Kinerja simpang pun dapat diketahui dengan melihat nilai derajat kejenuhan, tundaan dan peluang antrian yang terjadi di persimpangan $\mathrm{Jl}$. Boulevard -Jl. Adhyaksa Baru.

Tabel 9. Perilaku Lalu lintas

\begin{tabular}{|c|c|c|c|c|c|}
\hline $\begin{array}{c}\text { Kapasitas } \\
\text { Dasar } \\
\text { (Co) } \\
\text { Smp/jam }\end{array}$ & $\begin{array}{c}\text { Kapasitas } \\
\text { (C) } \\
\text { Smp/jam }\end{array}$ & $\begin{array}{c}\text { Arus } \\
\text { Lalulintas } \\
\text { (Q) } \\
\text { Smp/jam }\end{array}$ & $\begin{array}{l}\text { Derajat } \\
\text { Kejenuhan } \\
\text { (DS) }\end{array}$ & $\begin{array}{l}\text { Tundaan } \\
\text { (D) } \\
\text { Det/smp }\end{array}$ & $\begin{array}{c}\text { Peluang Antrian } \\
\text { (QP) } \\
\%\end{array}$ \\
\hline 2900 & 33398 & 29378 & 0,880 & 14,972 & $61,17-31,06$ \\
\hline
\end{tabular}

(sumber: hasil perhitungan,2018)

\section{KESIMPULAN}

Dengan melihat hasil perhitungan analisis masalah yang terjadi pada simpang tak bersinyal $\mathrm{Jl}$. Boulevard - Jl. Adhyaksa Baru dan Jl. Boulevard - Bougenvile dapat ditarik kesimpulan bahwa :

Simpang tak bersinyal jalan Boulevard - jalan Adhyaksa baru memiliki kapasitas 33.397 smp/jam sedangkan pada simpang jalan Boulebard - jalan Bougenville memiliki kapasitas 4277 smp/jam.

Pada kondisi eksisting, arus lalu lintas pada simpang tak bersinyal pertama (Q) sebesar $21.949 \mathrm{smp} / \mathrm{jam}$ dengan derajat kejenuhan (DS) $0,657<0,85$, sedangkan pada tahun 2023 dengan kapasitas simpang yang sama, arus lalu lintas pada simpang tak bersinyal pertama diprediksi sebesar $33.398 \mathrm{smp} / \mathrm{jam}$ dengan derajat kejenuhan $0,88>0,85$. Hal ini menunjukkan bahwa kondisi pada tahun 2023 sudah diatas batas jenuh yang ditetapkan MJKI. Nilai ini 
menunjukkan bahwa kapasitas kinerja simpang tersendat, maka diperlukan penanganan pada simpang tersebut untuk mengurangi tingkat kepadatan lalu lintas

Pada kondisi eksisting arus lalu lintas pada simpang tak bersinyal kedua (Q) sebesar 1.935,6 smp/jam dengan derajat kejenuhan $0,453<0,85$, sedangkan pada tahun 2023 dengan kapasitas simpang yang sama, arus lalu lintas pada simpang tak bersinyal kedua diprediksi sebesar 2.592,5 smp/jam dengan derajat kejenuhan $0,606<0,85$. Hal ini menunjukkan bahwa pada tahun 2023 kinerja simpang masih cukup baik dimana dengan asumsi kondisi jalan yang tidak ada perubahan, masih mampu menampung volume kendaraan yang melintas.

\section{DAFTAR PUSTAKA}

1. Adisasmita,R., 2007, Perencanaan Jaringan Trasnportasi, Buku Ajar Untuk Mahasiswa Pascasarjana Universitas Hasanuddin.

2. Anonimus, Manual Kapasitas Jalan Indonesia (MKJI), Departemen Pekerjaan Umum Direktorat Jenderal Bina Marga, Jakarta 1997.

3. Morlock, E. K, Pengantar Teknik dan Perencanaan Transportasi, Erlangga, Jakarta 1991

4. Tamin, Ofyar. Z., Perencanaan dan Pemodelan Transportasi., edisi ke-2 Bandung 2000

5. Penjelasan Undang-undang Pemerintah Republik Indonesia nomor 38 Tahun 2004 Tentang Jalan.

6. Peraturan Menteri Perhubungan Republik Indonesia nomor 14 tahun 2006 Tentang Manajemen dan Rekayasa Lalu Litas di Jalan.

7. Peraturan Pemerintah Republik Indonesia nomor 34 tahun 2006, Tentang Jalan

8. Y. Haranto P, Studi Kinerja Simpang Tak Bersinyal Yang Tidak Sebidang di Kota Makassar (Studi Kasus Simpang Jalan Urip Sumoharjo - Jalan Leimena), Universitas Hasanuddin 2004.

9. Marchyano Beltsazar Rnada Kabi. dkk. ,Analisis Kinerja Simpang Tanpa Sinyal (Studi Kasus : Simpang Tiga Ringroad - Maumbi), Universitas Sam Ratulangi Manado, 2015.

10. Dito Ashar Saputra, dkk, Analisis Kinerja Simpang Bersinyal KM 4 di Kota Makassar, Universitas Hasanuddin, 2017

11. Lasthreeida J.H, Medis Surbakti, Evaluasi Kinerja Simpang Bersinyal (Studi Kasus : Jl. Ir. H. Juanda - Jl. Imam Bonjol), Universitas Sumatera Utara, 2013

12. Lamhot Hasudungan Sariaman Sitanggang, Joni Harianto. Analisa Kinerja Simpang Bersinyal (Studi Kasus Jl. K. H. Wahid Hasyim - Jl. Gajah Mada), Universitas Sumatera Utara, 2014

13. Naraodee Salatoom, A study of a flyover - Bridge - Improved Intersection, Songkla University, Hat Yai Songkla, Thailand, 2014

14. Ahmad Husain, Maryuani, As'ad Munawir, and Lambang B Said, An Analysis of The Economic, Value of Left-Turn System at the Insersectiom for Urban Enfironmental Benefit, Australian Journal of Basic and Applied Sciences 11;2, AENSI 2017.

15. Asma Massara, Abdul Hakim, Achmad Wicaksono, and Lambang B Said, Correlation Level of Motorcycle and Travelling Characteristics Using Regression Model, IJSRP International Journal of Scientific and Research Publication 8;4, www.ijsrp.org, 2018

16. Ahmad Husain, Maryuani, As'ad Munawir and Lambang B Said Efficiency of Vehicle Operational Coas at Intersection with Geometric Widening Design in Makassar, South Sulawesi, JEAS Journal of Engineering and Applied Sciences 13;9, Medwell Journals Scientific Researsh Publishing Compani, 2018

17. Lambang B Said, Syaifullah, Dampak Pembangunan Infrastruktur Jalan terhadap Perekonomian Wilayah, Lembaga Literasi Dayak (LLD), Palangkaraya, 2017

18. Lambang B Said, Hanafi Ashad, Suryani A Muid, Transportation Model to Minimize Distribution Cost of Construction Materials, Australian Journal of Basic and Applied Sciences 9:23 AENSI, 2015

19. Lambang B Said, Abdul Kadir Salim, and Andi Alifuddin, A Mixture of Traffic Circle and Underpass to Increase Capacity of Intersection, JEAS Jurnal of Engineering and Applied Sciences 12:8, Medwell Journals Scientific Researsh Publising Company, 2017 